\title{
Nasalização regressiva heterossilábica (NRH) da vogal /a/ acentuada em PE
}

\author{
Shanyi Lao, Celeste Rodrigues \& Fernando Brissos \\ FLUL-CLUL-ULisboa
}

\begin{abstract}
:
According to the autosegmental model adopted by Mateus \& Andrade (2000), the nasal vowel in Portuguese, in words such as cinco, lã and campo, is a phonetic form derived from a phonological oral vowel plus a nasal autosegment $\mathrm{N}$ in the same syllable. However, we can also notice the nasalization in words such as cãma, cẽna and cünha in Portuguese, although not often in the standard language. This phenomenon is an heterosyllabic regressive nasalization $(\mathrm{NRH})$, in which the nasal consonant of the onset nasalizes the previous vowel. In Brazilian Portuguese, there are more studies related to NRH than in European Portuguese and most of them treat it as a phonetic phenomenon (Câmara Jr., 1970; Battisti, 1997; Botelho, 2007). Moraes \& Wetzels (1992) find NRH more frequently in the stressed syllable and with the palatal consonant $/ \mathrm{n} /$, but its frequency varies in different dialects. Therefore, this paper aims to analyze the variation of $\mathrm{NRH}$ in Mainland Portugal and the phonological processes that go together with it, focusing particularly on the structure $/ \mathrm{a} /[+\mathrm{ac}] . \mathrm{C}_{[+\mathrm{nas}]}(/ \mathrm{m} /, / \mathrm{n} /, / \mathrm{n} /)$. We collected occurrences that contain the target structure from the corpus Linguistic-Ethnographic Atlas of Portugal and Galicia and our analysis is based on the phonetic transcriptions performed by CLUL dialectologists. By calculating the percentage of NRH in each locality and making dialectal maps, the results show that: i) NRH can be found almost throughout the entire territory; ii) it has a greater frequency in Northwest (mainly with the consonant /n/), Beira Baixa, Alentejo, and Algarve; iii) multiple phenomena transform the phonological segments into different phonetic shapes; iv) in a diachronic analysis, the changing path of /a/ in Portuguese in this structure is: $[\mathrm{a}] \rightarrow[\tilde{\mathrm{a}}] \rightarrow[\tilde{\mathrm{e}}] \rightarrow[\mathrm{e}]$, which shows that the elevation of /a/ follows the NRH. Dialects, then, choose between one of these phonetic variants.
\end{abstract}

Keywords: NRH, Portuguese dialects, dialectal maps, phonetic modifications, phonological analysis

\section{Introdução}

Tradicionalmente, o principal foco de investigação da nasalidade em português incide na discussão das "vogais nasais" como em campo ou lã, que podem ser consideradas resultantes de nasalização regressiva tautossilábica do autossegmento N (Mateus \& Andrade, 2000). O tipo de nasalidade que pretendemos estudar neste trabalho é diferente, porque a nasalização ocorre com o envolvimento de duas sílabas contíguas. Por exemplo nas palavras cama, cana e apanha, a nasalização ocorre na sílaba que precede a consoante nasal do ataque silábico seguinte. Por outras palavras, trata-se de uma nasalização regressiva heterossilábica (NRH).

Em português do Brasil (PB), o fenómeno tem sido tratado como uma assimilação fonética ou alofónica (Câmara Jr., 1970; Moraes \& Wetzels, 1992; Battisti, 1997; Botelho, 2007), no qual um ataque silábico, em posição intervocálica, permite que a nasalidade se propague, regressivamente, para a esquerda ao núcleo da sílaba anterior (Moraes, 2013:12). De acordo com Moraes \& Wetzels (1992:155), esta nasalidade carateriza-se por: i) ocorrer frequentemente em sílaba tónica - ou seja, "stress-induced nasalization", tal como referido por Goodin-Mayeda (2016:60) - ex. cãno, sendo encontrado também o fenómeno em sílaba pretónica de palavra derivada, ex. cãninho, e, em palavras proparoxítonas, ex. átõna; ii) surgir mais facilmente com a consoante palatal /n/ do que as outras consoantes nasais, ex. em cũnhado mas não em cúmulo, embora a sílaba-alvo seja átona na primeira palavra enquanto é tónica na segunda; iii) variar nos diferentes dialetos, por exemplo, 
existindo nas tónicas e pretónicas no Nordeste do Brasil, só nas tónicas no Rio de Janeiro, e não existindo nas tónicas em São Paulo.

Em português europeu (PE), ainda não existe uma descrição exaustiva do fenómeno em análise. De acordo com Mateus \& Andrade (2000), que adota o modelo autossegmental (abreviado como MA), as vogais nasais são tratadas como resultado da associação do autossegmento nasal $\mathrm{N}$ ao núcleo precedente na mesma sílaba. Caso se considere esta nasalidade heterossilábica, temos de reconhecer que, no PE padrão, ela parece ser mais superficial e variável, uma vez que é um processo fonológico que se aplica apenas em certos casos e, provavelmente, apenas em alguns falantes. Do ponto de vista diacrónico, Pimenta (2019:118-120) propõe que, não é necessário distinguir as análises dos dois tipos de nasalidade, já que as vogais nasais podem ser também resultado da acumulação da $\mathrm{NRH}$, dando exemplos como lana $>$ lãa $>$ lã, manu $>$ mão ${ }^{1}$. Para que exista o reforço da nasalização fonética no núcleo, foi necessário que a consoante - $n$ - intervocálica só caísse deixando o traço nasal em condições de nuclearizar - ou seja, tornando a vogal nasal (pp.185). Seja qual for o tipo de nasalização, a sua natureza é o espraiamento regressivo da nasalidade da consoante para a vogal precedente, heterossilábica (cama) ou tautossilábica (campo).

Quanto às propriedades e extensão territorial da NRH em Portugal, os primeiros trabalhos da dialetologia portuguesa mostram que a NRH também apresenta grande variação: i) Vasconcelos (1901:75-76, §40) registou o fenómeno na região interamnense, em quase toda a área de Trás-os-Montes, nas Beiras, no Alentejo e no Algarve, mas não na região de Lisboa ou Setúbal. Mais detalhadamente, Vasconcelos (1928; 1985), ao referir a NRH, indica que a vogal $a$ é mais facilmente nasalizada do que as outras vogais; ii) Vásquez Cuesta \& Mendes da Luz (1980:63) afirmam que este fenómeno é muito intenso no Minho (principalmente na zona ocidental), Trás-os-Montes, Beira Alta, Beja e Algarve; iii) tendo organizado os dados de Vasconcelos (Opúsculos, Vol. VIII, em fase adiantada de preparação), Florêncio (2001) regista a NRH no interior do Baixo Alentejo e no Centro Interior (Portalegre); iv) Brissos $(2015: 1008)^{2}$ regista intensidade da NRH no Centro-sul do país, nomeadamente no Centro Interior, em Quintos (Beja interior) e no Algarve. Mas esta nasalização não recebeu da parte de Cintra (1971) grande destaque. Além da NRH, existem outros fenómenos variáveis de região para região a ela associados, por exemplo, a manutenção do grau de abertura de $a$, que convive com a NRH no dialeto interamnense (Vasconcelos, 1928), ao passo que no padrão existe uma elevação de $a$ para [e].

É de notar que está por estudar mais aprofundadamente a variação da NRH nos dialetos no território de Portugal continental. Considerando tudo isto, pretendemos perceber melhor o fenómeno que atua na estrutura V.C [+nasal] $(/ \mathrm{m} /, / \mathrm{n} /, / \mathrm{n} /)$, por meio de análise quantitativa das ocorrências de NRH, nos materiais da base de dados do Atlas Linguístico-Etnográfico de Portugal e da Galiza (abreviado como ALEPG) - o atlas linguístico nacional, que constitui um corpus rico para o estudo da variação linguística (Saramago, 2006; Brissos, 2015:1021). Para que o artigo fosse exequível, era necessário proceder à restrição da informação a analisar, nomeadamente, à vogal /a/ em sílaba acentuada, cujos dados são suficientemente abundantes em quase todos os pontos de inquérito e em face de todas as consoantes nasais. Procuraremos nomeadamente: i) verificar o comportamento e a distribuição do fenómeno em Portugal continental, ao sistematizar, calcular e cartografar os dados - o último sendo o objetivo principal deste trabalho; ii) identificar e agrupar as formas variantes de realização fonética relevantes em cada região; iii) analisar a NRH e os processos fonológicos relacionados com ela de acordo com o MA, por exemplo, a fusão de duas vogais (coanha, c['on] $\mathrm{a}^{3}$ ), a modificação de qualidade da vogal /a/ (enxame, enx['Em]e) ou a inserção de semivogais (roldana, rold['ãjn]a).

\footnotetext{
${ }^{1}$ De acordo com Sampson (1999:14-15), a nasalização alofónica (devida a coarticulação) pode reforçar-se ou enfraquecer-se, o que causa resultados diferentes percetivamente. Além dos exemplos referidos acima, existem outras possibilidades como corona $>$ corõa $>$ coroa, senu $>$ sẽo $>$ seio, em que a nasalidade se enfraqueceu e perdeu com a síncope de $-n-$.

${ }^{2} \mathrm{O}$ trabalho só se refere às variedades do Centro e Sul, sem a variedade padrão.

${ }^{3}$ As transcrições fonéticas de palavras extraídas da base de dados do ALEPG mantêm a marcação do acento na posição em que os transcritores o colocaram.
} 


\section{Metodologia}

Tendo o presente trabalho o objetivo de conhecer melhor a variação da NRH no território continental, optou-se pelo corpus mais abundante e de melhor qualidade hoje em dia disponível - o ALEPG, do qual todas as ocorrências relativas à estrutura-alvo $/ \mathrm{a} /[+\mathrm{ac}] . \mathrm{C}[+\mathrm{nas}](/ \mathrm{m} /, / \mathrm{n} /, / \mathrm{n} /)$ são extraídas na nossa pesquisa. Nesta secção, é feita uma descrição breve desta fonte de dados, dos símbolos específicos que se utilizam nas formas fonéticas e dos critérios de tratamento a que estes foram sujeitos.

\subsection{Introdução ao ALEPG}

Tendo sido dirigido inicialmente por Luís F. Lindley Cintra, o ALEPG é um projeto linguístico galegoportuguês, que continuou para além do seu falecimento. O fim principal deste corpus é o de recolher materiais lexicais das variedades dialetais das áreas referidas, simultaneamente registando outras caraterísticas linguísticas, de fonética, fonologia, sintaxe, morfologia, entre outras (Saramago, 2006). A rede do ALEPG foi construída de acordo com o grau de variação linguística regional e a densidade populacional respetiva e conta atualmente com 212 pontos de inquérito que se dispersam no português e em zonas de Espanha junto à fronteira. O presente trabalho concentra-se nas 176 localidades que se situam em Portugal continental, cujas designações e siglas correspondentes são apresentadas no Anexo 1 (Saramago, 2006:292-294, Anexo 3a).

A recolha de dados começou em 1973 e acabou em 2004, utilizando um questionário baseado numa vasta lista de conceitos a inquirir em cada inquérito, ou seja, grosso modo em cada localidade 4 . Como o âmbito da recolha era muito amplo e havia termos em rápido desaparecimento, foi reduzido o tamanho do questionário em 1990 - só cerca de metade dos conceitos inquiridos inicialmente permaneceu até ao final - para acelerar o processo de recolha de dados. O mapa na Figura $1^{5}$ mostra as localidades em que foi aplicado o inquérito original, marcadas por círculo preenchido a preto e aquelas em que foi aplicado o inquérito ajustado, marcadas por um círculo oco (baseado no mapa de Saramago, 2006:291, Anexo 3). A diferença do número de conceitos inquiridos em cada ponto de inquérito pode causar divergências de quantidade dos dados dos conceitos nos diferentes pontos. Não deixa, no entanto, de ser a maior e mais fiável base de dados para utilizar com os presentes objetivos.

Os falantes envolvidos na investigação são informantes tidos como linguisticamente "conservadores", pois o seu perfil satisfazia as condições seguintes: ter idade acima dos 50 anos à data da entrevista; possuir no máximo o nível de instrução correspondente à escolaridade primária; ter os pais e, eventualmente, o cônjuge provenientes da mesma localidade ou de localidades vizinhas; ter uma boa capacidade de resposta às perguntas do questionário; e não ter saído frequentemente ou por muito tempo da localidade. Após a recolha das gravações de todas as entrevistas, foi efetuada pela equipa do projeto a transcrição fonética e ortográfica dos dados e construído um banco de dados digital. Para este trabalho recorremos à transcrição fonética efetuada pelos investigadores do Centro de Linguística da Universidade de Lisboa (CLUL), que se encontra na base de dados.

\footnotetext{
${ }^{4}$ Os conceitos são itens lexicais baseados nos «campos semânticos adaptados ao agrupamento ideológico proposto por Hallig e von Wartburg para o francês» (Saramago, 2006:282), de duas naturezas: léxico comum e léxico especializado, nomeadamente associados à agricultura e à agropecuária.

${ }^{5}$ Os pontos assinalados por letras A-L situam-se no território espanhol e não são, portanto, marcados na Figura 1.
} 
Shanyi Lao, Celeste Rodrigues e Fernando Brissos

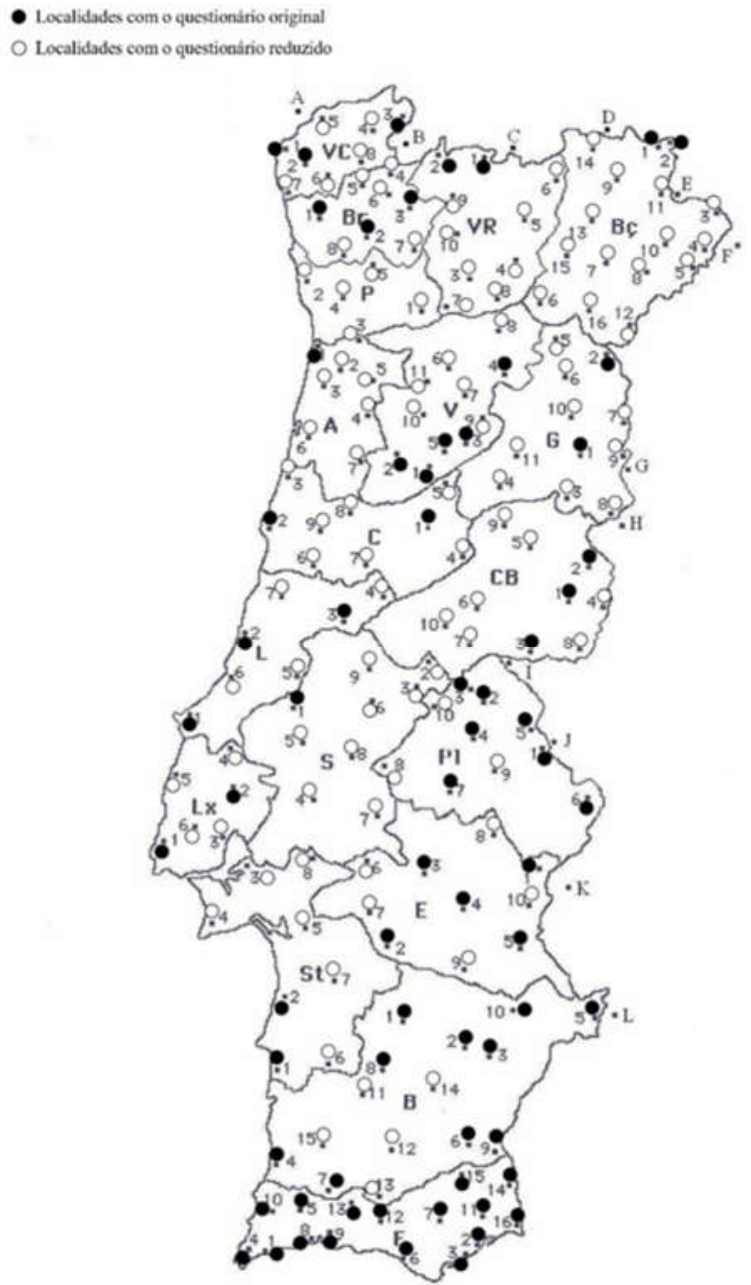

Figura 1 - Localidades com inquéritos reduzidos e originais do ALEPG

\subsection{Representação fonética no ALEPG}

Como a análise parte das formas fonéticas das vogais, é relevante introduzir o sistema próprio que o ALEPG utiliza para representar a realização fonética de diversos timbres, umas vezes ligeira outras fortemente diferenciados. Os símbolos específicos (e diacríticos) aplicados nas vogais são apresentados na Figura 2, com explicitação das variantes relevantes da vogal /a/ no contexto fonológico de que nos ocupamos. Notaremos que a indexação das representações fonéticas do ALEPG ao diagrama da Figura 2 é, muito naturalmente, aproximada, uma vez que a notação fonética do ALEPG foi construída especificamente para as variedades do português europeu. Referência especial merece o facto de, e, terem um raio de ação especialmente amplo, que vai até perto do eixo articulatório central. 


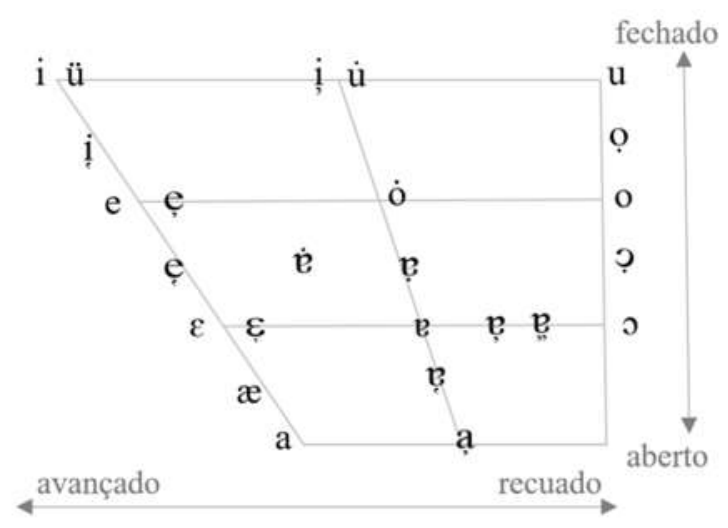
[ạ] Realização ligeiramente recuada de [a]
[ن்] Realização ligeiramente avançada de [e]
[e] Realização ligeiramente recuada de [ $\mathrm{e}]$
[e] Realização fortemente recuada de [e]
[e] Realização mais aberta de [e]
[e] Realização mais fechada de [e]
[ẹ:] Alongamento de [e]
[e] realização mais aberta de [e]
[?] realização mais fechada de [0]
[o] realização mais fechada de [o]

Figura 2 - Esquema articulatório dos timbres do ALEPG

\subsection{Critérios de seleção, contagem e cartografia de dados}

Tendo tido acesso aos dados do ALEPG, selecionámos os conceitos que possuem a estrutura-alvo - a vogal $a$ acentuada antes de uma consoante nasal heterossilábica $(/ \mathrm{m} /, / \mathrm{n} /, / \mathrm{n} /)$, de categorias não verbais - nomes, adjetivos e determinantes (com os conceitos indicados no Anexo 2). Com estes conceitos, fizemos pesquisa no banco digital e assim obtivemos as ocorrências/variantes de todos os pontos de inquérito. Também foram anotadas em ficheiros Excel informações detalhadas como as correspondentes a: transcrições ortográficas, transcrições fonéticas, código dos informantes, localidades, fenómenos fonológicos observados em cada ocorrência, entre outras. Salienta-se que: i) estão envolvidos na base de dados do ALEPG 175 dos 176 pontos de inquérito em Portugal continental, afora o ponto B6 (Beja - Álamo), cujo tratamento de dados ainda não terminou; ii) se tomam em consideração os pontos em que se fala, além do português, também o mirandês e o barranquenho, respetivamente em Bragança e em Barrancos, apesar de as formas destas variedades serem excluídas da análise final. Obtivemos no final 4472 ocorrências com todas as estruturas em foco para análise.

Tendo os dados sistematizados, contámos os valores absolutos das ocorrências nasalizadas e os das ocorrências não nasalizadas de todos os pontos de inquérito, em função da presença das três consoantes nasais, e calculámos as suas respetivas percentagens. Assim, não só podemos observar, de modo mais direto, as frequências da NRH de cada estrutura e de cada localidade, mas também os números nos dão um contributo importante para a preparação do passo seguinte, a cartografia dos dados. Porém, caso a localidade tenha um valor total de ocorrências inferior ou igual a 2, os seus dados são considerados pouco relevantes, já que, neste caso, os valores não são suficientes para apresentar uma clara tendência de presença vs. ausência do fenómeno. Portanto, são analisadas detalhadamente apenas as localidades que possuem dados de quantidade válida - superior a 3.

Quanto ao desenho dos mapas aqui apresentados, utilizámos círculos com o mesmo contorno preto mas diferentes preenchimentos para representar vários tipos de pontos. Os pontos "inválidos" (com dados menos relevantes, como já referido) são preenchidos por cor cinzenta, enquanto os válidos se separam em 4 grupos de escala, de acordo com os valores percentuais: $0 \% \sim 24 \%, 25 \sim 49 \%, 50 \% \sim 74 \%$ e $75 \% \sim 100 \%$, cujo preenchimento é, respetivamente, branco, pontilhado, listado e preto. Isto possibilita a nossa observação da distribuição regional da NRH pelo território português. 


\section{Apresentação dos dados}

Esta secção apresenta e descreve os dados sistematizados, sendo composta por três partes: i) as estatísticas globais de todo o país, ii) os mapas dialetais e iii) as formas variantes das três estruturas fonológicas /a.m/, /a.n/, /a.n/.

\subsection{Estatísticas globais}

Tendo os dados sistematizados nas folhas de cálculo, observa-se, de modo mais objetivo, quanta NRH ocorre em cada uma das estruturas. Na Tabela 1, resumem-se os valores absolutos das ocorrências de S (Sim, com espraiamento de $\mathrm{NRH}$ ) e das de $\mathrm{N}$ (Não, sem espraiamento de $\mathrm{NRH}$ ) e os seus valores percentuais $\mathrm{S} \%$ e $\mathrm{N} \%$ da estrutura-alvo com a vogal /a/. Observa-se que: i) as três estruturas têm ocorrências de quantidade considerável - mais de mil; ii) o valor total é muito mais baixo no caso de /a.m/ (1027) do que nas outras duas estruturas /a.j/ (1713) e /a.n/ (1666) ${ }^{6}$; iii) as percentagens da NRH (S\%) das diferentes estruturas (com consoantes nasais distintas) são quase idênticas: $58 \%$ de /a.m/, 59\% de /a.n/ e de /a.n/, aproximando-se de $60 \%$. Em síntese, os dados obtidos confirmam que a vogal /a/ é facilmente nasalizada na estrutura-alvo e que o comportamento da NRH não varia significativamente em função do ponto de articulação das três consoantes nasais.

\begin{tabular}{|c|c|c|c|c|c|}
\hline & total & $\mathrm{S}$ & $\mathrm{N}$ & $\mathrm{S} \%$ & $\mathrm{~N} \%$ \\
\hline /a.m/ & 1027 & 591 & 436 & $58 \%$ & $42 \%$ \\
\hline /a.n/ & 1666 & 986 & 680 & $59 \%$ & $41 \%$ \\
\hline /a.p/ & 1713 & 1014 & 699 & $59 \%$ & $41 \%$ \\
\hline
\end{tabular}

Tabela 1 - Valores de ocorrências de diferentes estruturas fonológicas

\subsection{Mapas dialetais}

Nesta parte, observamos mais em detalhe as circunstâncias específicas da NRH de cada estrutura fonológica nas diferentes localidades. Pretendemos fazer uma descrição segura e sintética dos mapas que foram desenhados de acordo com os critérios de cartografia já indicados (Metodologia, cf. Secção 2), para identificar as zonas que manifestem mais a NRH e aquelas em que o fenómeno ocorra raramente. Neste caso, iremos referir as designações antigas das províncias de Portugal na delimitação administrativa de 1936, em comparação com as atuais dos distritos do ALEPG (Saramago, 2006:291, Anexo 3, Figura 3). Os dois mapas encontram-se reproduzidos na Figura 3.

\footnotetext{
${ }^{6}$ A desproporção de quantidade de dados relaciona-se com vários fatores, como: i) o inquérito reduzido do ALEPG (cf. Secção 2.1) pode diminuir o número de ocorrência; ii) o volume de conceitos é desequilibrado em relação à presença das diferentes consoantes.
} 

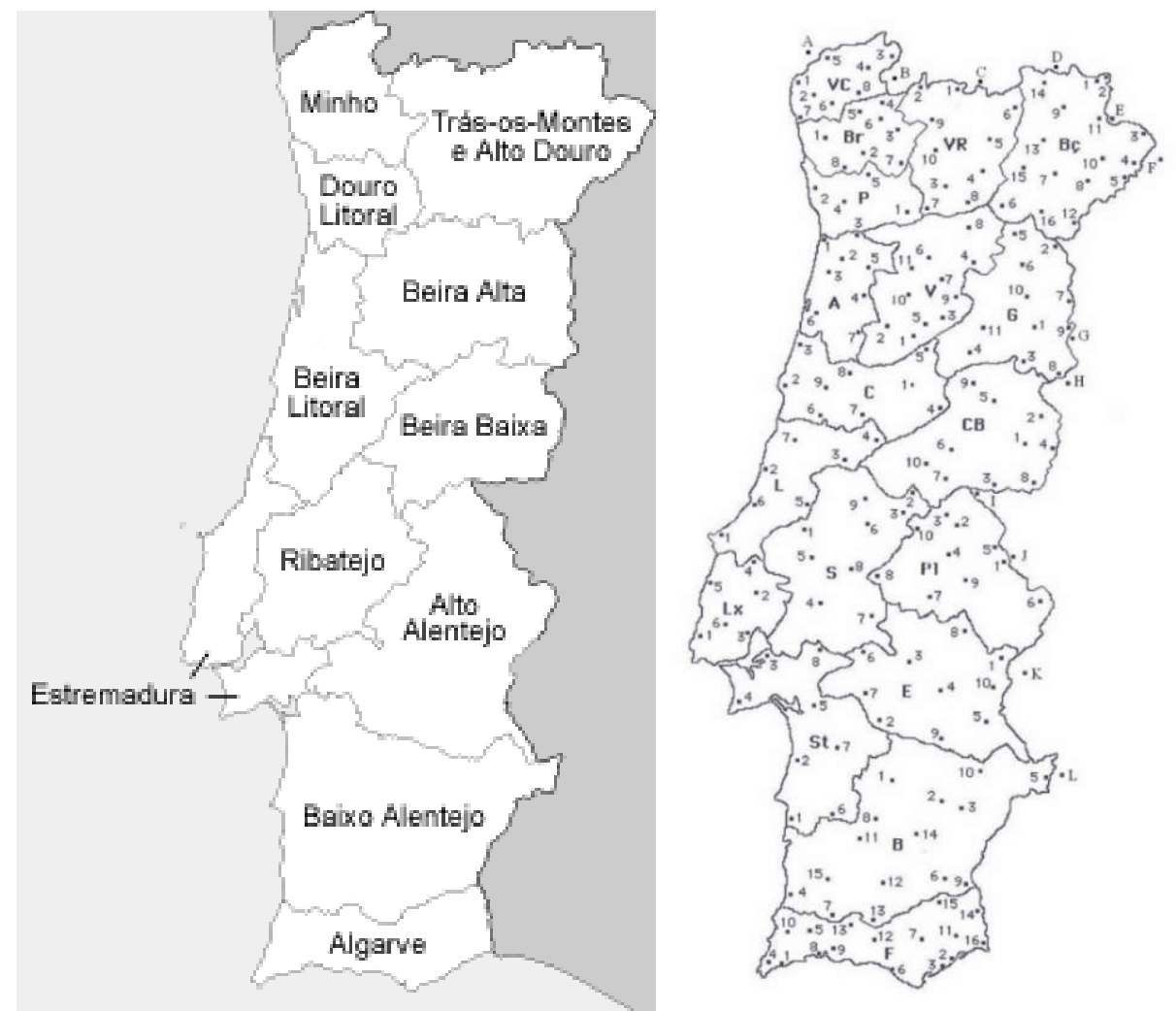

Figura 3 - Mapa administrativo de $1936^{7}$ e mapa do ALEPG (Saramago, 2006:291, Anexo 3)

Seguem abaixo os três mapas (apresentados nas Figuras 4, 5 e 6) correspondentes às estruturas /a.m/, /a.n/ e /a.j/, os quais apresentam a proporção de NRH de cada uma das estruturas. Nota-se, de um modo geral, que não há grande diferença na distribuição de NRH relacionada com a presença de uma ou de outra das três consoantes nasais e que quase todas as localidades são marcadas conforme os critérios por nós adotados (exceto poucos pontos de inquérito a cinzento no mapa da estrutura /a.m/, que possui relativamente menos dados em relação às outras duas). Mais em detalhe, observa-se uma vasta zona com a NRH, cuja maior intensidade parece incidir no Noroeste (Minho e Douro Litoral), Beira Baixa, Alentejo e Algarve, em que há mais pontos a preto e listados. Quanto à região em que se nasaliza menos, é evidente uma faixa que se estende de Nordeste (Trásos-Montes e Alto Douro), em direção sudoeste para a Beira Litoral, e que termina na margem meridional da Estremadura, onde, não obstante, se encontram certos pontos com frequente nasalização. Apesar dos pontos em comum, existem duas divergências assinaláveis entre os mapas das três estruturas: i) a estrutura /a.n/ mostra maior destaque da NRH no centro do país; ii) a estrutura /a.p/ apresenta mais pontos a preto no Noroeste. Em suma, é semelhante o comportamento da NRH da vogal /a/ com as três consoantes, mas varia ligeiramente em determinadas zonas e com certas consoantes.

\footnotetext{
${ }^{7}$ Fonte do mapa administrativo: https://pt.wikipedia.org/wiki/Províncias_de_Portugal.
} 
$0 \% \sim 24 \%$
25\% $249 \%$
(1) $50 \% \sim 74 \%$
- $75 \% \sim 100 \%$
Valor de dados $\leq 2$

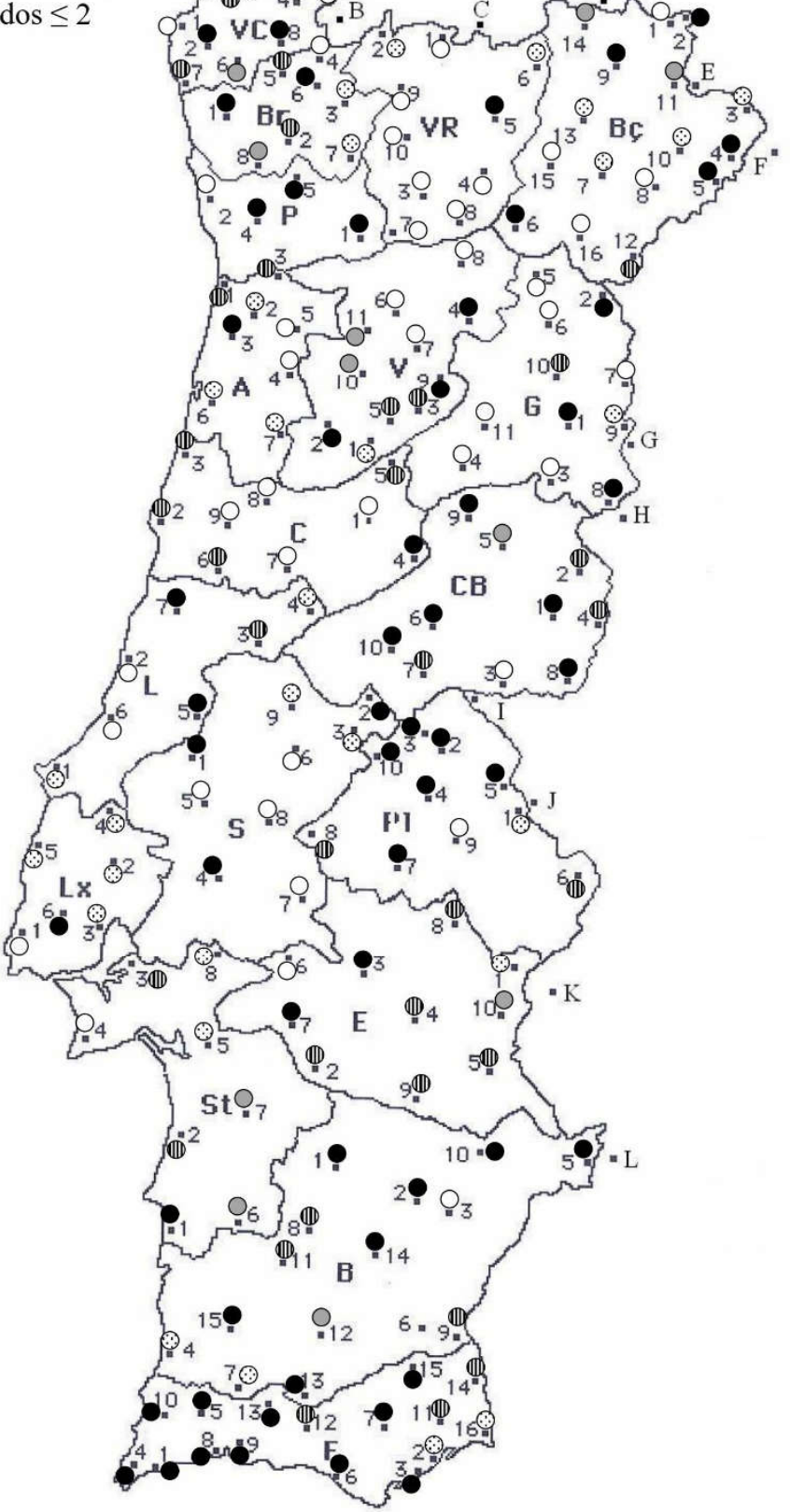

Figura 4 - Intensidade de NRH da estrutura /a.m/ em Portugal continental 
○ $0 \% \sim 24 \%$

(-) $25 \% \sim 49 \%$

(1D) $50 \% \sim 74 \%$

- $75 \% \sim 100 \%$

Valor de dados $\leq 2$

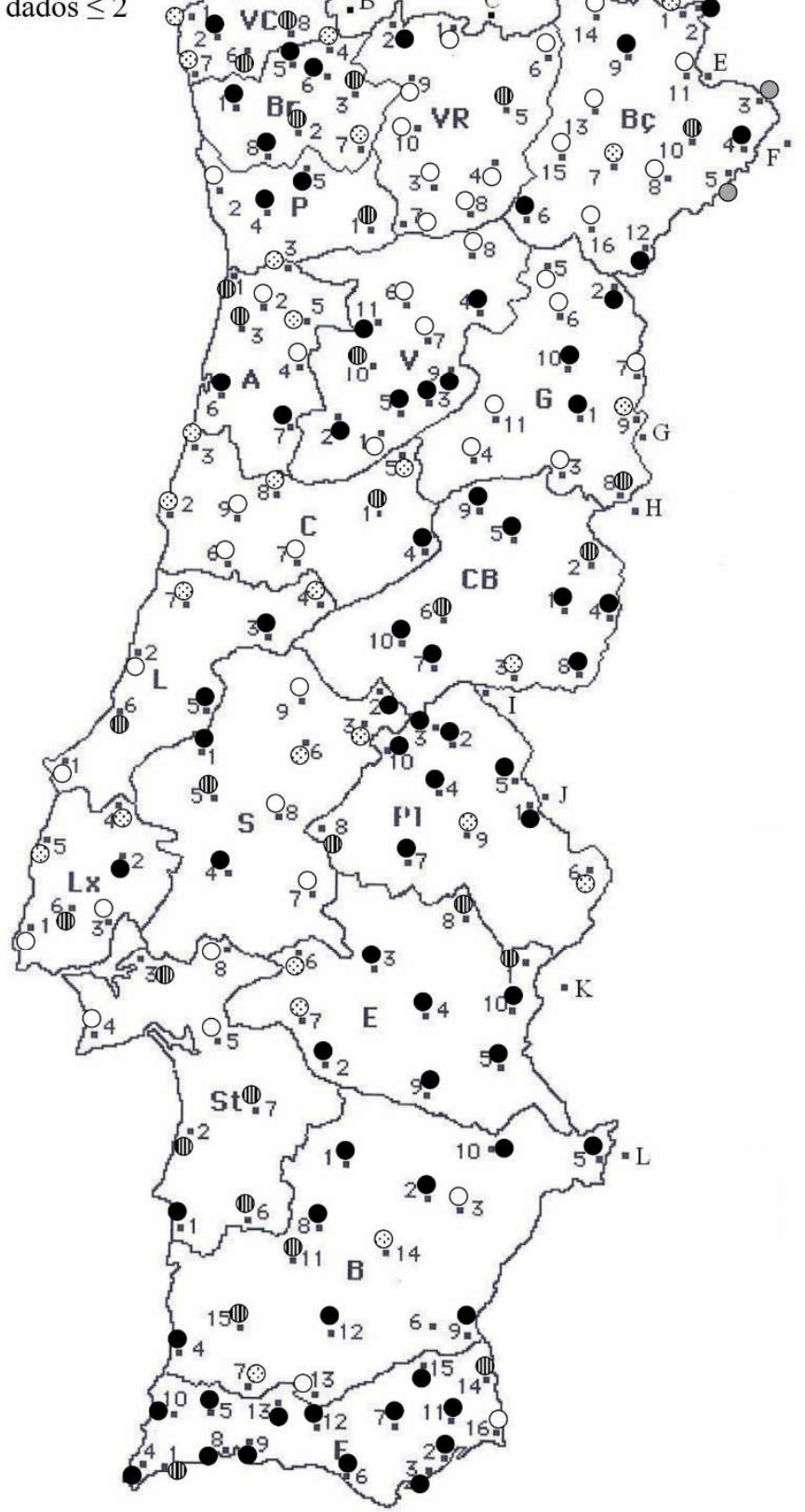

Figura 5 - Intensidade de NRH da estrutura /a.n/ em Portugal continental 
○ $0 \% \sim 24 \%$

() $25 \% \sim 49 \%$

(11) $50 \% \sim 74 \%$

- $75 \% \sim 100 \%$

Valor de dados $\leq 2$

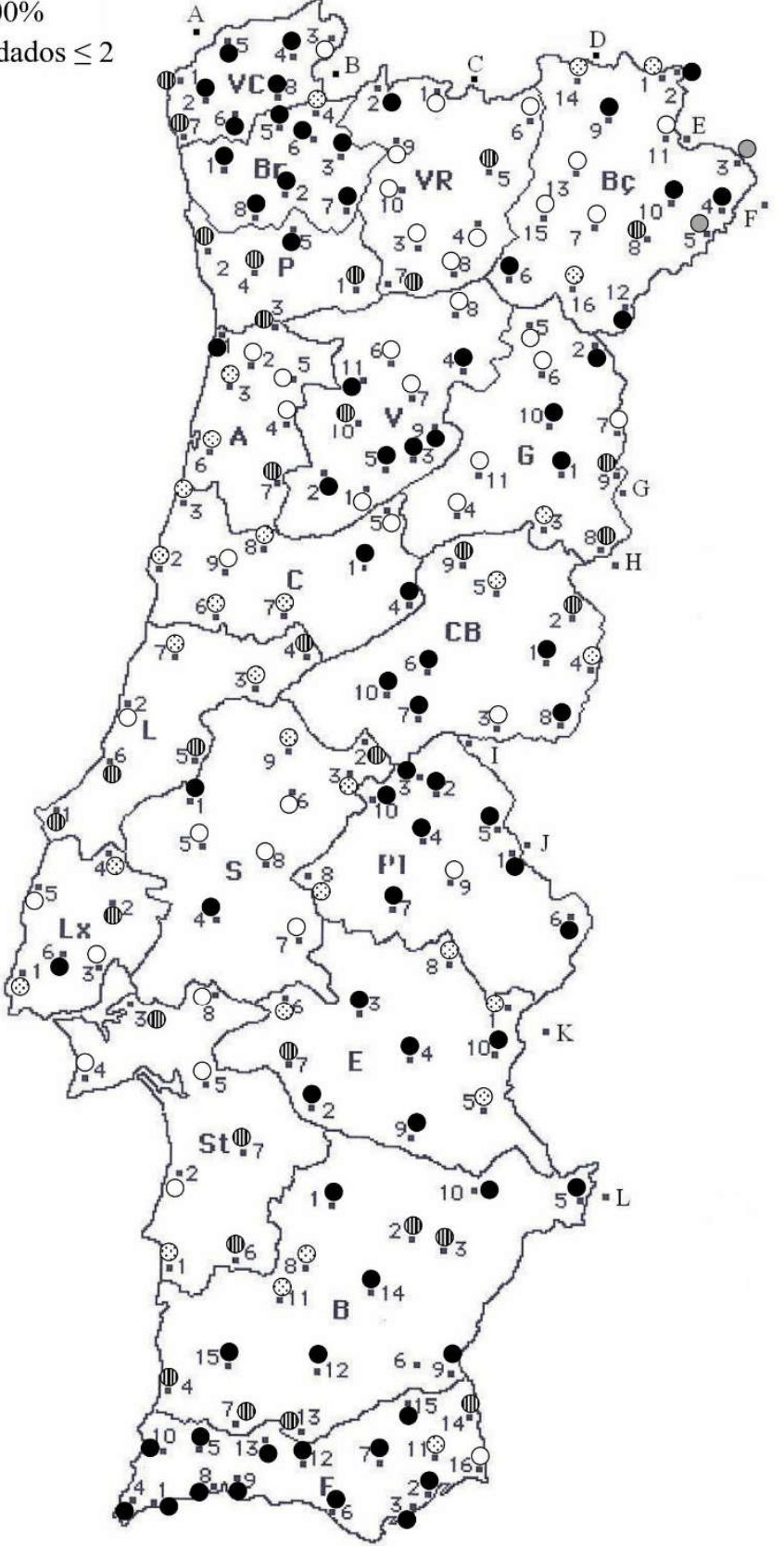

Figura 6 - Intensidade de NRH da estrutura /a.n/ em Portugal continental 


\subsection{Formas variantes das estruturas fonológicas /a.m/, /a.n/, /a.p/}

Embora o alvo de investigação seja a NRH, encontram-se variantes fonéticas abundantes que resultam possivelmente de aplicação de diferentes processos fonológicos. Esses processos podem conviver ou relacionarse com a NRH, por isso, faremos aqui uma breve apresentação dos mesmos. Os fenómenos podem ser reunidos em três grupos: i) modificação da vogal (coanha, c['on]a; enxame, enx['Em]e), ii) modificação da consoante (rebanho reb['ẽn]o) e iii) inserção de semivogais (roldana, rold['ãjn]a).

\subsubsection{Modificação da vogal}

De acordo com o esquema da Figura 1, fizemos a contagem das ocorrências nasalizadas e desnasalizadas de todas as variantes de cada estrutura e obtivemos a Tabela 2.

\begin{tabular}{|c|c|c|c|c|c|c|c|c|c|c|c|c|c|c|c|c|c|c|}
\hline \multirow{2}{*}{\multicolumn{3}{|c|}{$\begin{array}{c}\mathrm{VF} \\
\text { fone }\end{array}$}} & \multicolumn{15}{|c|}{$/ \mathrm{a} /$} & \multirow[b]{2}{*}{ total } \\
\hline & & & [e] & [ẹ] & {$[\varepsilon]$} & [a] & [a] & [v] & {$[\dot{\boldsymbol{E}}]$} & {$[\mathrm{e}]$} & {$[\mathrm{v}]$} & [ẹ:] & {$[\mathrm{v}]$} & [e] & [0] & [?़] & {$[\mathrm{o}]$} & \\
\hline & $/ \mathrm{m} /$ & $\mathrm{S}$ & & 1 & & 16 & 2 & 108 & 6 & 393 & & & 66 & & & & & 592 \\
\hline \multirow{5}{*}{ C } & & $\mathrm{N}$ & 1 & & 3 & 20 & 1 & 43 & 4 & 358 & & & 6 & & & & & 435 \\
\hline & $/ \mathrm{n} /$ & S & & 1 & & 22 & 1 & 142 & 6 & 672 & & 1 & 129 & 3 & 1 & & 9 & 986 \\
\hline & & $\mathrm{N}$ & 2 & & & 40 & 1 & 66 & 7 & 534 & 2 & & 25 & 1 & & 1 & 2 & 680 \\
\hline & $/ \mathrm{n} /$ & $\mathrm{S}$ & 1 & & & 26 & & 188 & 9 & 682 & & & 101 & & & 1 & & 1007 \\
\hline & & $\mathrm{N}$ & 1 & & & 14 & & 61 & 13 & 583 & & & 9 & & 14 & & 1 & 695 \\
\hline & total & & 5 & 2 & 3 & 138 & 5 & 608 & 45 & 3222 & 2 & 1 & 336 & 4 & 15 & 2 & 12 & 4395 \\
\hline
\end{tabular}

Tabela 2 - Apresentação das variantes fonéticas de /a/

Além da forma elevada de /a/ do padrão, [e], que também se encontra muito frequentemente pelo país (será discutida na Secção 4.2.1), observámos três fenómenos de modificação principais, que ocorrem de modo semelhante com as três consoantes: o de abertura, o de avanço (palatalização) e o de recuo (velarização). Dentro destes fenómenos, ainda há diferentes graus de alteração, com as respetivas regiões marcadas pelas abreviaturas S/N (i.e., Sim/Não) para representar a presença/ausência da NRH:

i. Fenómeno de abertura: [e] - Norte (mas mais frequente no Noroeste) e Castelo Branco (S);

[a], [a] - Noroeste;

ii. Fenómeno de avanço: $[\dot{\mathrm{e}}]$ - em Vila Real $(\mathrm{N})$ e Viseu $(\mathrm{S})$;

$[\varepsilon],[\mathrm{e}],[\mathrm{e}]$ - Alentejo (a NRH existe só na terceira forma apresentada);

iii. Fenómeno de recuo: $[\tilde{\mathfrak{e}}],[\tilde{\mathscr{\vartheta}}]$ - Centro Interior e Algarve (S);

$$
\begin{aligned}
& \text { [o] - Alentejo e Algarve (S), } \\
& \text { [o], [๑] - Centro Interior }(\mathrm{N})^{8} \text {. }
\end{aligned}
$$

\subsubsection{Modificação da consoante nasal}

Nas formas do português, existem apenas quatro ocorrências com modificação de /n/ para [n] em Setúbal e Santarém. Veja-se a Tabela 3 abaixo. Tendo muito poucas ocorrências, a possibilidade de constituírem erros de transcrição é razoável. Como não justificam a sua análise neste momento, não será feita a análise fonológica destes casos.

\footnotetext{
${ }^{8}$ As variantes labiais [o], [o], [ొ̣] ocorrem só com as consoantes coronais /n/ e /n/, principalmente, por causa da fusão de duas vogais nos conceitos coanha e o ano passado, o que será discutido na Subsecção 4.2.5.
} 


\begin{tabular}{|c|l|c|l|l|l|}
\hline EF & Modificação & Quantidade & Conceito - ocorrência & Transcrição & Distribuição \\
\hline /a.j/ & $/ \mathrm{j} / \rightarrow[\mathrm{n}]$ & \multirow{2}{*}{4} & lenha miúda - tanganhos; rebanho & {$[\tilde{\mathrm{e} n}, \tilde{\text { enn }]}$} & St7, S2 \\
\cline { 4 - 6 } & & & coanha - coanho & [jjn, ojn] & S7, St8 \\
\hline
\end{tabular}

Tabela 3 - Apresentação das variantes fonéticas de /a/

\subsubsection{Inserção de semivogal}

A inserção de semivogal apresenta-se na Tabela 4. Torna-se óbvio que a quantidade de ocorrências não é muito alta, no total 30. Concentra-se principalmente no Noroeste e Castelo Branco. Em pormenor, estas ocorrências podem agrupar-se em inserção de: i) $[\mathrm{j}] /[\mathrm{j}]^{9}$ antes do núcleo; ii) $[\mathrm{w}] /[\mathrm{w}]$ antes do núcleo; iii) $[\mathrm{j}] /\left[{ }^{\mathrm{j}}\right]$ a seguir ao núcleo; e iv) $[\mathrm{w}] /[\mathrm{w}]$ a seguir ao núcleo. Destas, as formas variantes do terceiro grupo são as mais frequentemente encontradas.

\begin{tabular}{|c|c|c|c|c|c|}
\hline Semivogal & Estrutura & Quantidade & Conceito-ocorrência & Transcrição fonética & Distribuição \\
\hline$[\mathrm{j}] /[\mathrm{j}]$ antes & /a.m/ & 1 & ama-uma ama & 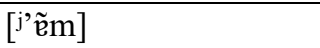 & CB1 \\
\hline \multirow{3}{*}{$\begin{array}{l}{[\mathrm{w}] /[\mathrm{w}]} \\
\text { antes do } \\
\text { núcleo }\end{array}$} & \multirow[b]{2}{*}{ /a.n/ } & \multirow[b]{2}{*}{5} & tutano; cano-(os) & 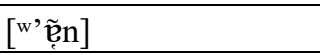 & $\mathrm{Br} 5, \mathrm{P} 4$ \\
\hline & & & $\begin{array}{l}\text { cana-(são) canas; } \\
\text { ramo-(os) canos; (um) }\end{array}$ & [w’ãn] & $\mathrm{Br} 2$ \\
\hline & $/ a . n /$ & 1 & banha & [" $\left.{ }^{\mathrm{w}} \tilde{\mathrm{p}} \mathrm{j}\right]$ & CB10 \\
\hline \multirow{3}{*}{$\begin{array}{l}{[\mathrm{j}] /[\mathrm{j}] \text { a }} \\
\text { seguir ao } \\
\text { núcleo }\end{array}$} & /a.n/ & $5(2 S / 3 N)$ & roldana; ratazana & [ãjn, ָ̣jjn, ajn, pẹn] & $\begin{array}{l}\mathrm{Br} 5, \mathrm{VC} 2 \\
\mathrm{VC} 6, \mathrm{P} 2\end{array}$ \\
\hline & \multirow[b]{2}{*}{ /a.p/ } & \multirow{2}{*}{$16(12 \mathrm{~S} / 4 \mathrm{~N})$} & coanha & [ojn, ojn] & S7, St8 \\
\hline & & & $\begin{array}{l}\text { anho; banha; castanha; } \\
\text { rebanho }\end{array}$ & 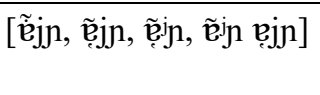 & $\begin{array}{l}\text { Braga, } \\
\text { Porto, }\end{array}$ \\
\hline $\begin{array}{l}{[\mathrm{w}] /[\mathrm{w}] \text { a }} \\
\text { seguir ao } \\
\text { núcleo }\end{array}$ & /a.n/ & 2 & tutano; o ano passado & {$\left[\tilde{\mathfrak{p}}^{\mathrm{w}} \mathrm{n}, \tilde{\mathrm{p}}^{\mathrm{w}} \mathrm{n}\right]$} & Br6, CB7 \\
\hline
\end{tabular}

Tabela 4 - Apresentação das inserções de semivogais

\subsubsection{Síntese}

Tendo obtido os resultados acima descritos na amostra analisada (cf. Subsecção 2.1), podemos resumir o que se observou do seguinte modo: i) a NRH da vogal /a/ acentuada seguida das diferentes consoantes nasais possui valores percentuais relativamente elevados e idênticos (aproximadamente 60\%), no português continental; ii) os mapas das três estruturas comportam-se de modo semelhante, apresentando a NRH em quase todo o país, apesar de ter frequência variável em função das regiões - menor incidência na área compreendida entre o Nordeste e a Beira Litoral, Estremadura e Ribatejo, e maior incidência no resto do país, embora se tenha de destacar a maior intensidade da nasalização com $/ \mathrm{n} /$ no centro do país e com /n/ no Noroeste; iii) acompanhando frequentemente a NRH, encontram-se outros fenómenos que com ela convivem, os quais podem agrupar-se em três categorias, modificação de qualidade vocálica, modificação de qualidade consonântica e inserção de semivogais.

\footnotetext{
${ }^{9}$ Os símbolos das semivogais em tamanho reduzido, $\left[{ }^{j}\right]$ ou [w], são utilizados pelos transcritores para assinalar a presença de sons semivocálicos percetivamente mais fracos do que o habitual.
} 


\section{Análise dos resultados}

Nesta secção, pretendemos efetuar a análise dos resultados de dois pontos de vista, o dialetológico e o fonológico.

\subsection{Análise dialetológica}

Relembra-se que, de acordo com as descrições anteriores, a NRH se encontra na maior parte do país, afora a região de Lisboa ou Setúbal (segundo Vasconcelos, 1901:75-76, §40), sendo mais forte no Minho, Trás-osMontes, Beira Alta, Beja e Algarve (de acordo com Vásquez Cuesta \& Mendes da Luz, 1980:63). Noutras obras destinadas a certas variedades, o fenómeno é assinalado por Florêncio (2001), no Baixo Alentejo interior e no Centro Interior, e por Brissos (2015:1008) em todo o Centro-Sul, com especial intensidade na região de Portalegre, no Baixo Alentejo interior e no Algarve.

Em comparação com estes estudos, os nossos dados confirmam que a estrutura com a vogal /a/ é alvo da NRH de modo mais intenso na zona do Noroeste (Minho e Douro Litoral), na Beira Baixa, no Alentejo e no Algarve, em que predominam os pontos com o valor percentual superior a 50\%. Pelo contrário, a nasalização apresenta pouca intensidade na região do Nordeste (Trás-os-Montes e Alto Douro), Beira Alta, Beira Litoral, Estremadura e Ribatejo, o que contraria as referências globais anteriormente mencionadas. Nas Beiras, apenas a Beira Baixa se destaca pela existência de forte NRH. A elevada frequência das ocorrências não nasalizadas nas estruturas-alvo que se registam nas regiões da língua padrão justifica o facto de a NRH não ser um fenómeno em grande destaque no PE contemporâneo. No entanto, pode estranhar-se o facto de o Nordeste partilhar esta caraterística com o padrão, devido à sua maior proximidade em termos geográficos e linguísticos com o Noroeste. Propomos aqui três possibilidades de interpretação para essa divergência: i) a dimensão do inquérito reduzido pode influenciar os resultados, na medida em que a faixa territorial de baixa nasalização é aquela onde este foi aplicado; ii) além disso, os dados que Vasconcelos (1901) e Vásquez Cuesta \& Mendes da Luz (1980) utilizaram são mais antigos do que os aqui analisados, pelo que o desfasamento entre corpora se pode dever, antes de mais, a um desfasamento temporal; iii) aqui analisa-se apenas a estrutura-alvo com a vogal /a/, enquanto os estudos anteriores não se focam em vogais e consoantes específicas - logo, pode haver outras vogais que são mais nasalizadas nestas regiões, o que deixa questões em aberto para investigação futura.

Por outro lado, observa-se que a consoante palatal /n/ só desencadeia mais frequentemente a NRH no Noroeste. Por isso, os dados do ALEPG não corroboram totalmente as conclusões de Moraes \& Wetzels (1992) para o PB, nomeadamente o facto de ser $/ \mathrm{n} / \mathrm{a}$ consoante que mais nasaliza a vogal da sílaba precedente. Por este motivo, sugerimos que i) há diferenças entre PE e PB no comportamento da NRH, sendo que ii) está por verificar se a consoante $/ \mathrm{n} /$ nasaliza com mais facilidade as outras vogais do que $/ \mathrm{a} /$.

Além disso, encontram-se nos dados do ALEPG alguns fenómenos nos conceitos observados que nos relembram observações anteriores de diversos autores: i) a velarização de /a/ no Centro Interior, Alentejo e Barlavento do Algarve - já referida por Cintra (1971) da variedade da Beira-Baixa e Alto-Alentejo e da variedade do Barlavento algarvio; ii) a ditongação de /a/ no Minho e Douro Litoral, em que Cintra (1971) reporta a ditongação crescente em /e/ e /o/ da variedade do Baixo-Minho e Douro Litoral.

\subsection{Análise fonológica autossegmental}

Baseando-se no estudo de Andrade e Kihm (1987), Mateus \& Andrade (2000) adota o MA para descrever a nasalização tautossilábica em português. Trata as vogais nasais fonéticas como vogais orais fonológicas que sofrem um processo de nasalização, possível graças à presença do $\mathrm{N}$ flutuante, remanescente da consoante nasal em coda herdada do latim, que se associa ao núcleo. Salienta-se que o MA é um modelo multilinear e multiplanar que permite a análise das propriedades - sendo consideradas autónomas e possivelmente móveis, não fixas numa posição estrutural específica - de diferentes fiadas em hierarquia, tais como a fiada segmental, 
a silábica e a métrica (Goldsmith, 1990). Tendo isso em mente e sabendo da autonomia do traço nasal em português, pretendemos adotar o modelo para descrever a NRH e as alterações que com ela convivem, utilizando também a geometria de traços (Clements e Hume, 1995) e a teoria de subespecificação radical (Archangeli, D. B., 1988).

\subsubsection{NRH e elevação de /a/}

A estrutura-alvo da NRH deste trabalho pode ser representada abreviadamente como: $/ \mathrm{a} /[+\mathrm{ac}] . \mathrm{C}_{[+\mathrm{nas}]}$; esta contém, portanto, uma vogal antes de uma consoante nasal heterossilábica. De modo diferente do que se passa na estrutura da nasalidade tautossilábica (ou seja, o $\mathrm{N}$ flutuante associa-se ao núcleo), aqui considera-se que o traço [nasal] se associa ao núcleo. Mais detalhadamente, a existência de uma assimilação por parte da vogal acentuada do traço [nasal] da consoante do ataque, mantendo-se esta consoante habitualmente inalterada. A

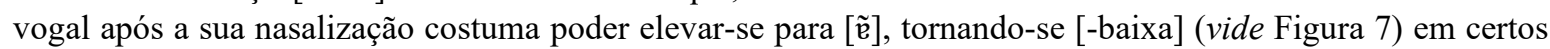
dialetos (nos quais se inclui o padrão). A elevação de /a/ também acontece na nasalização tautossilábica, o que parece suceder antes de $/ \mathrm{n} / \mathrm{e} / \mathrm{m} /$ desde há mais de quatro séculos (segundo Pimenta, 2019:108).

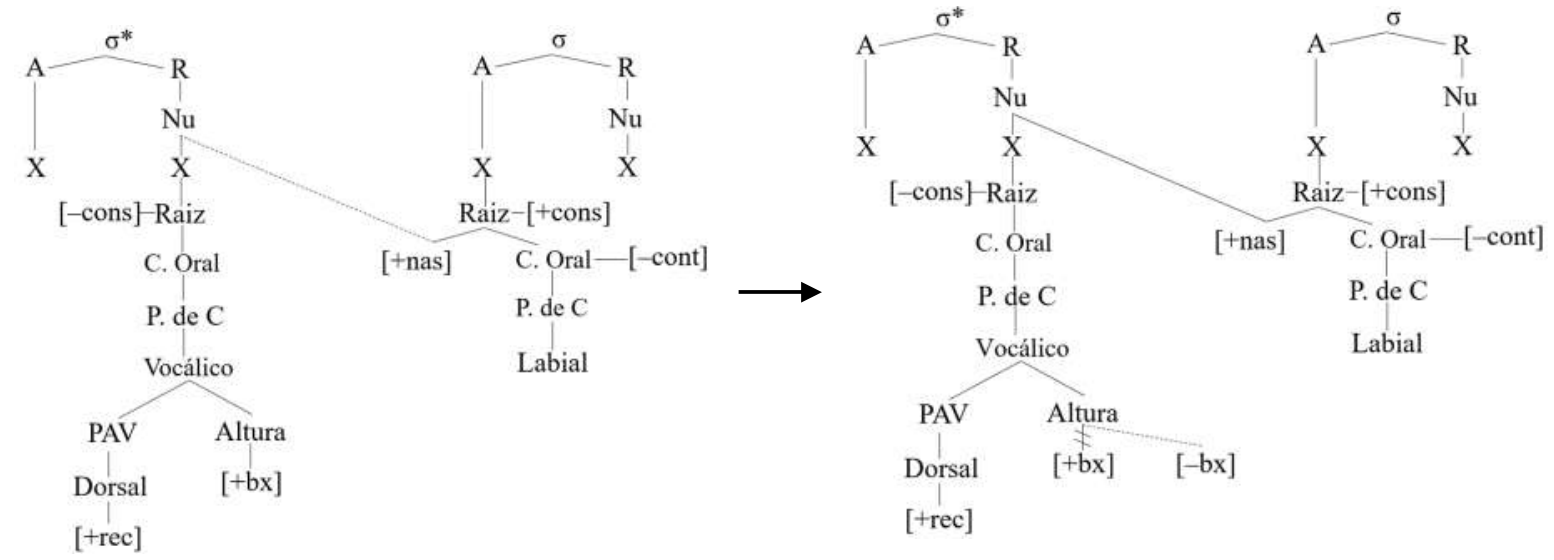

Figura 7 - Representação de NRH e elevação de /a/ na palavra cama (c['ẽm]a) ${ }^{10}$

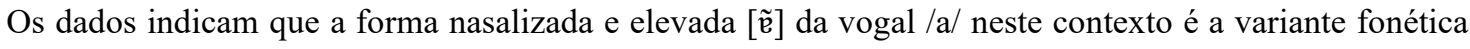
mais frequente em todo o país, não obstante existirem formas abertas como [a] e [ã] ou a forma desnasalizada $[\mathfrak{e}]$ em determinadas regiões. Tendo em conta a existência de variação com todas estas realizações fonéticas, parece-nos claro que a vogal /a/ pode ter sido alvo de uma transformação gradual ao longo do tempo com várias etapas: em primeiro lugar, a vogal /a/ assimila a nasalização da consoante seguinte ([ã]) e, por via disso, pode

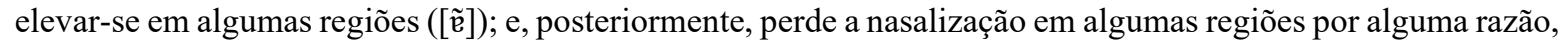
por enquanto, ainda não apurada. Supõe-se a seguinte ordem desta evolução: /a/ $\rightarrow[\mathrm{a}] \rightarrow[\tilde{a}] \rightarrow[\tilde{\mathrm{e}}] \rightarrow[\mathrm{e}]$, por ser a que faz mais sentido tendo em conta a natureza dos segmentos e a respetiva distribuição no território. Estas distintas formas são selecionadas por falantes de diferentes regiões: o Noroeste possui [a] e [ã], exibindo portanto as duas fases mais antigas da estrutura; Trás-os-Montes, Beira Alta, Beira Litoral, e Estremadura preferem [e], encontrando-se por isso na fase mais recente da cadeia evolutiva da estrutura; e de resto, o que

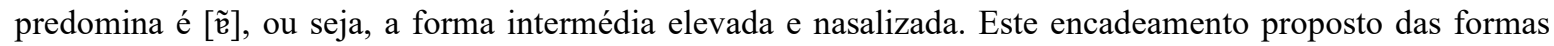
fonéticas permite explicar o facto de a NRH estar muito mais presente no território do que as descrições

\footnotetext{
${ }^{10} \mathrm{O}$ símbolo * indica o acento. PAV e PAC representam, respetivamente, Lugar de articulação vocálica e Lugar de articulação consonântica.
} 
anteriores sugeriam, o de haver muito geralmente elevação da vogal, em consequência da NRH, além do de a forma $[\mathfrak{e}]$ ser a mais inovadora na língua e se exponenciar na região abrangida pela variedade linguística padrão.

\subsubsection{Palatalização e velarização}

A palatalização e a velarização de /a/, que correspondem ao fenómeno de recuo-avanço que observámos, são alguns dos processos que afetam o núcleo e normalmente estão relacionados com a harmonia vocálica. $\mathrm{O}$ fenómeno de harmonia afeta a vogal-alvo, torna-a mais semelhante a uma outra vogal na estrutura da palavra (a pretónica, no caso dos exemplos enxame e roldana).

Em relação ao processo de palatalização, colocam-se aqui duas hipóteses de interpretação para o caso de enxame: i) a vogal coronal pretónica /e/ partilhará o seu ponto de articulação com a vogal tónica na sílaba seguinte e, assim, a vogal /a/ deixa de ser dorsal para ser coronal (Figura 8); ou ii) a consoante /J/ espraia a sua especificação Coronal[-anterior] e a vogal /a/ assume a realização [e]. No caso do exemplo gadanha, a palatalização do /a/ ocorre devido à presença do /n/ seguinte, tornando a vogal coronal (Figura 9) ${ }^{11}$.

No caso da velarização, por exemplo, em roldana, o traço labial da vogal pretónica associa-se também ao núcleo da estrutura-alvo, /a/ torna-se um [o], ganhando então o traço Labial (Figura 10).

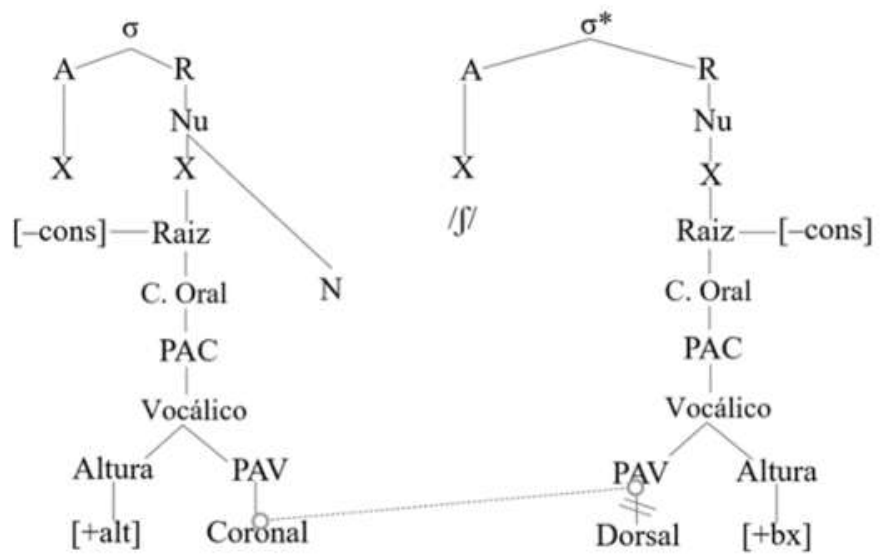

Figura 8 - Representação de palatalização de /a/ em enxame (enx['Em]e)

\footnotetext{
${ }^{11}$ A abertura da vogal dependerá da realização ou não da elevação provocada pela NRH. Nestes dois exemplos, a NRH não foi assinalada na transcrição da base de dados do ALEPG.
} 


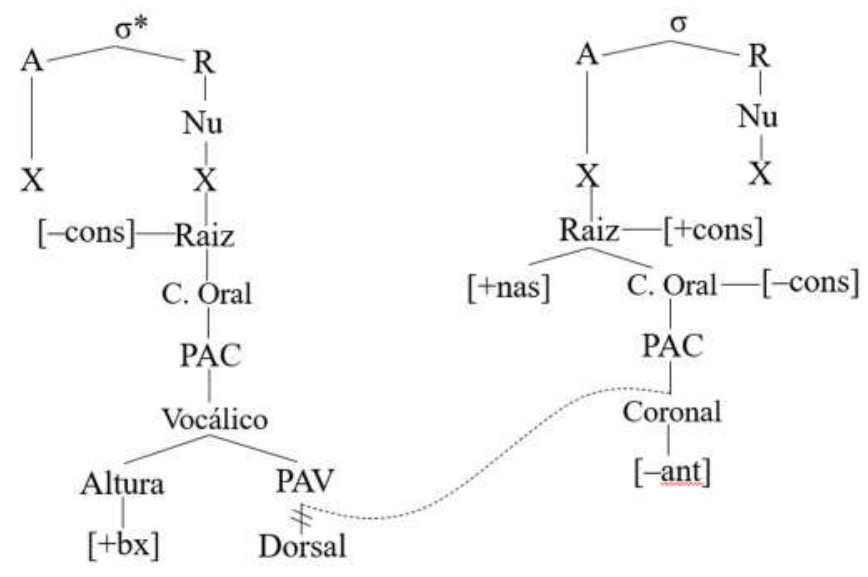

Figura 9 - Representação de palatalização de /a/ em gadanha (gad['en]a)

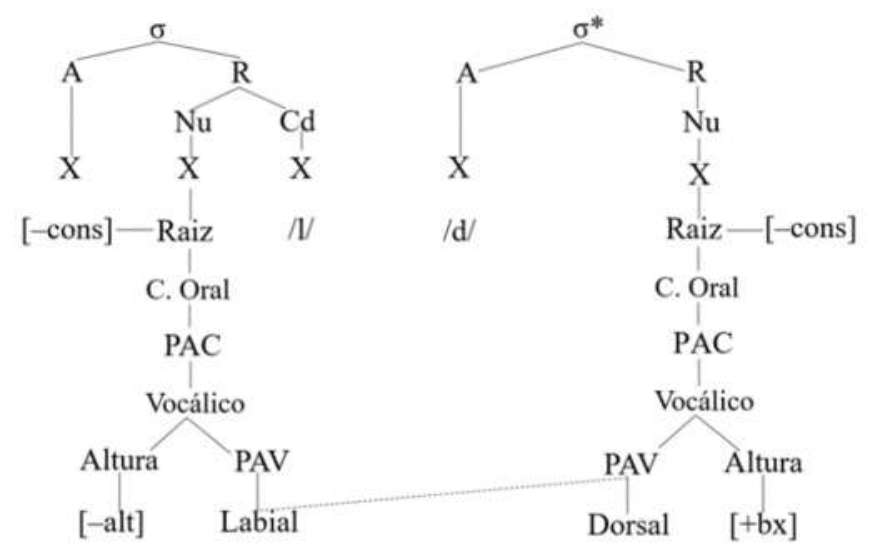

Figura 10 - Representação de velarização de /a/ em roldana (rold['on]a) $)^{12}$

\subsubsection{Inserção de semivogal}

As semivogais [j] e [w] e as suas formas mais fracas, ${ }^{[\mathrm{j}]}$ e [w], podem ser inseridas à esquerda ou à direita da vogal acentuada na estrutura-alvo. No primeiro caso, mesmo que não haja muitas ocorrências, a inserção à esquerda pode dar-se em uma ama [ume 'î̃me], onde se trata de inserção anti-hiática no interior de frase entoacional, mas também em banha ['b $\left.{ }^{\mathrm{w}} \tilde{\text { ̣̂n }} \mathrm{e}\right]$, em que a inserção de semivogal $w$ está relacionada com o ponto de articulação da consoante labial precedente e, ainda, em tutano [tut ${ }^{w}$ 'ẹnnu], a respeito do qual há duas hipóteses de interpretação a considerar. Por um lado, Segura e Saramago (1999:711) tratam casos de inserção deste tipo como ditongação crescente em sílaba tónica. Por causa de harmonização vocálica, a vogal pretónica da mesma palavra provoca a modificação do núcleo acentuado, por intermédio de inserção de uma semivogal. Contudo, isto parece não esclarecer porque é que a semivogal deve com a vogal formar um ditongo em vez de constituir uma articulação secundária da consoante precedente, ou seja, porque tem de formar um núcleo ramificado

\footnotetext{
${ }^{12} \mathrm{Na}$ terminologia tradicional que aqui adotamos, a velarização corresponde ao efeito de recuo da língua. Salienta-se que, na formalização do processo, optamos por descrevê-la como labiovelarização, na medida em que a vogal /a/ além de velarizar se labializa.
} 
crescente - uma estrutura que a língua tende a evitar. É devido à falta de naturalidade dos ditongos crescentes em português que Rodrigues (2002a:421) propõe, alternativamente, que a semivogal epentética constitua uma articulação secundária - a labialização da consoante que antecede a vogal acentuada, por espraiamento no ponto de articulação da consoante do ataque (Figura 11). Desse modo, não existe a criação fonética de um ditongo crescente, uma estrutura que a língua portuguesa, de um modo geral, tendeu a rejeitar historicamente.

Por outro lado, as ocorrências com mais quantidade de dados são aquelas que têm a semivogal palatal inserida a seguir ao núcleo, quase sempre antes da consoante palatal / $\mathrm{n} /$. Este fenómeno é tratado por Rodrigues (2002b:10) como uma assimilação, no qual a consoante palatal transmite ao núcleo precedente a palatalidade na forma de um [j]. A seguir à vogal acentuada surge assim uma especificação do ponto de articulação da consoante com o traço Coronal não anterior (foneticamente, um [j]), como representado na Figura 12. Uma vez que a autora incluiu também o traço Dorsal não recuado, apesar de este ser redundante, optamos por reformular o processo sem a inclusão do mesmo.

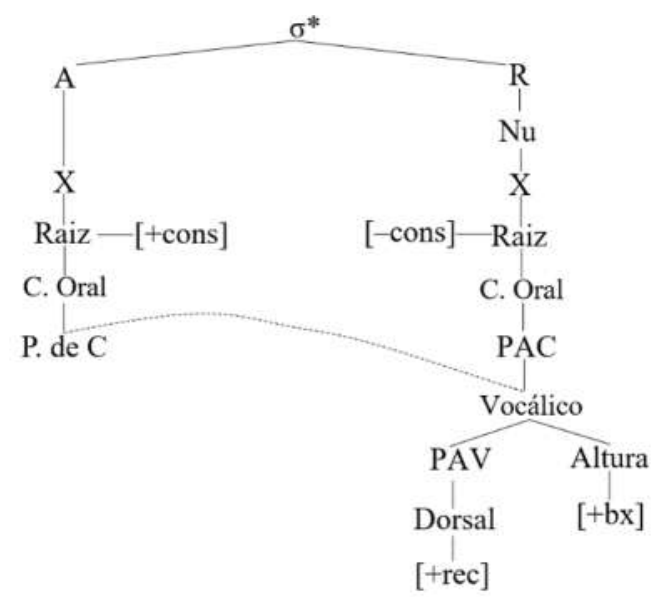

Figura 11 - Representação de associação do nó vocálico ao P. de C do ataque precedente

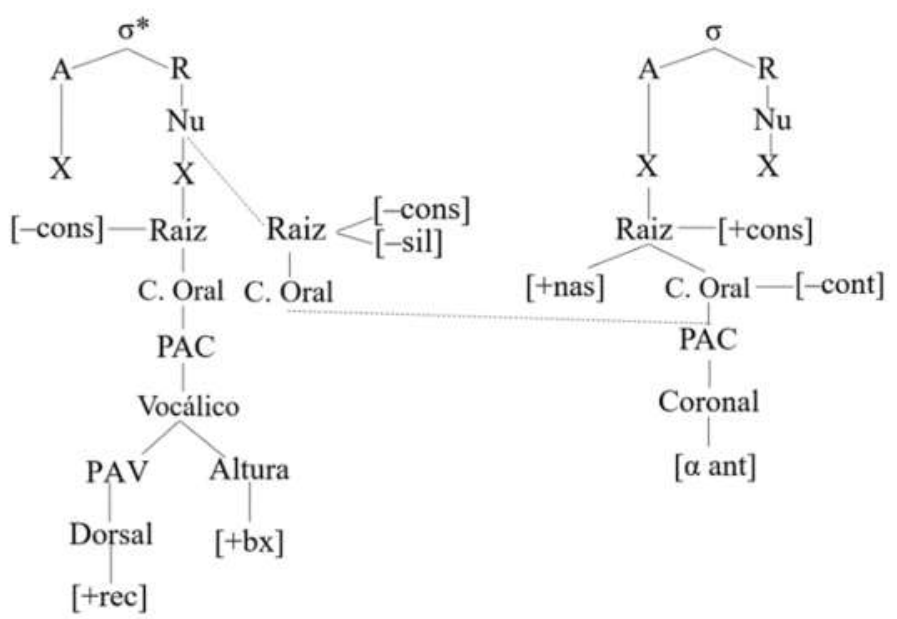

Figura 12 - Representação de inserção de semivogal a seguir ao /a/ acentuado 


\subsubsection{Fusão de duas vogais contíguas}

A fusão de vogais incide em determinadas palavras com vogais em hiato, como por exemplo coanha (ex. /ko.a.na/ $\rightarrow$ ['kəne]) e o ano passado (ex. /o/ /a.no/ $\rightarrow$ [õn]). Estas combinam uma vogal labial átona e uma vogal tónica dorsal e delas resulta apenas uma vogal com o traço labial acentuada. Um fenómeno idêntico também se observa no encontro vocálico /o.i/ (moinho ['mũnu]), pois, perante o encontro de duas vogais na mesma situação acentual, a vogal (ou a semivogal dela resultante) átona funde-se com a tónica fazendo com que o seu traço labial seja nesta preservado (ou seja, o traço Labial da primeira vogal ficou flutuante e depois associou-se à sua direita). No exemplo de coanha, representado na Figura 13, ocorre primeiro a semivocalização da primeira vogal e, a seguir, a fusão das sílabas com absorção do nó Labial (deixado flutuante pela primeira vogal) pela vogal tónica. Consideramos que esta fusão revela a maior importância do ponto de articulação labial da primeira vogal, face à manutenção dos traços das vogais do núcleo acentuado.

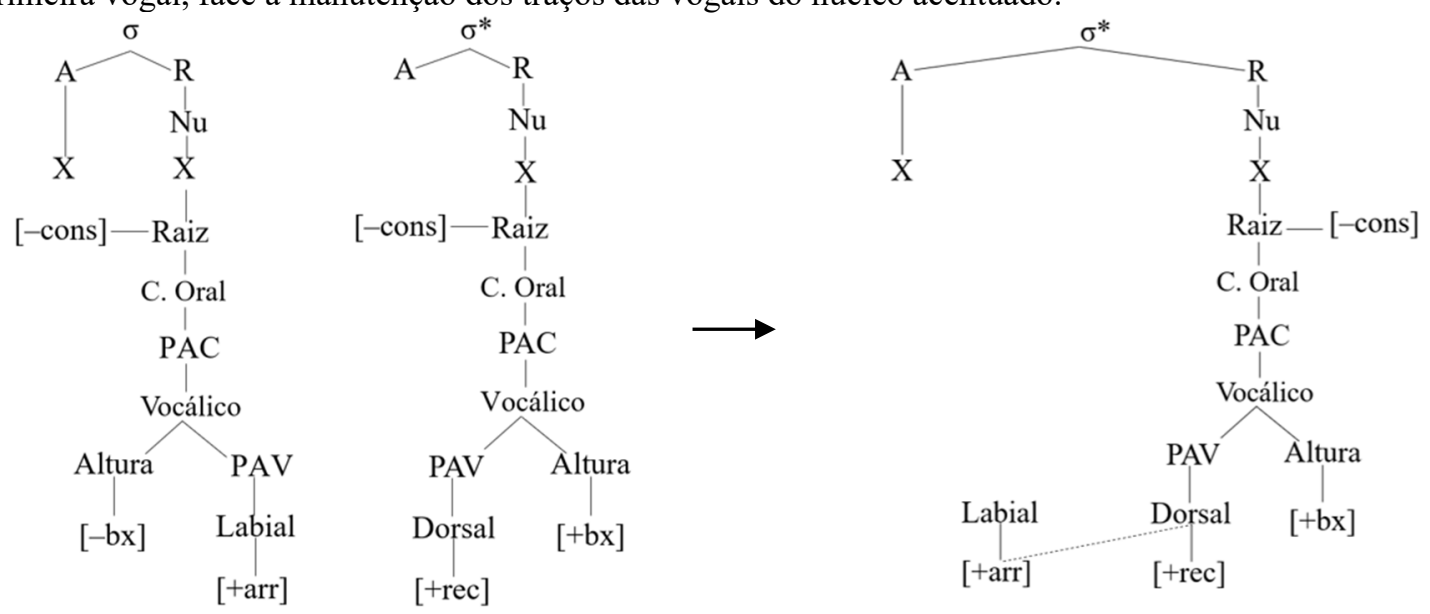

Figura 13 - Representação de fusão de duas vogais em coanha (c['on]a)

\section{Considerações finais}

Perante os resultados que obtivemos, podemos dizer que o fenómeno da NRH se encontra disperso no continente português, atingindo uma frequência elevada (cerca de 60\%), independentemente do ponto de articulação das consoantes nasais. A NRH nos dados analisados apresenta maior incidência no Noroeste (Minho e Douro Litoral), em particular, com a consoante palatal /n/; no Centro, é mais frequente com a consoante coronal /n/; e, pelo contrário, apresenta uma menor incidência com qualquer das consoantes no Nordeste (Trásos-Montes e Alto Douro), na Beira Alta, na Beira Litoral, na Estremadura e no Ribatejo.

A distribuição da presença e frequência relativa da NRH não coincide com as divisões dialetais de Cintra, pois o autor salientava uma oposição clara entre dialetos do Norte e dialetos do Centro e Sul do país que não registámos. Os nossos resultados, contudo, destacam claramente o Noroeste do resto do território. Esta é uma região que se considera habitualmente idiossincrática, sendo mais conservadora neste aspeto. Por outro lado, os resultados mostram, ainda, a existência de uma faixa diagonal contínua com pouca nasalização de Trás os Montes à Estremadura e Ribatejo. É, por isso, necessário atender à marcada diferença da NRH existente entre os dialetos setentrionais do Noroeste e do Nordeste. O Nordeste, apesar de poder ser tido como uma região linguística conservadora (devido, p. ex., à conservação de vários fonemas consonânticos, como o antigo sistema de quatro sibilantes não palatais: cf. Cintra, 1971: passim, esp. 109-110), apresenta um comportamento da 
nasalização regressiva heterossilábica mais próximo ao da Estremadura e do Ribatejo (tidas como inovadoras em fenómenos como a posteriorização do r-forte e a elisão de vogais átonas) do que ao do Minho e do Douro Litoral. Além disso, a existência complementar de elevada frequência da NRH no Centro Interior e Sul e em pontos dispersos nas áreas de menor frequência leva-nos a supor que o fenómeno deve ter sido mais abrangente no passado, ainda que hoje em dia não seja produzido ou percecionado por falantes da faixa diagonal no território, acima identificada, que abrange o padrão do PE. Por isso, propusemos uma ordem possível da evolução das formas fonéticas em português na estrutura estudada, [a] $>[\tilde{a}]>[\tilde{\mathrm{e}}]>[\mathrm{e}]$, que inclui como último passo à vogal média não nasalizada que precede a consoante nasal em ataque silábico. A dispersão no território destas formas variantes corrobora esta ordem de surgimento das variantes e mostra uma região Noroeste mais conservadora do que outras regiões que tradicionalmente são assim caracterizadas, sobretudo o Nordeste; temos aqui, possivelmente, mais um exemplo da forte personalidade dialetal da região que outros estudos já demonstraram e lhe permite manter e generalizar soluções linguísticas diferentes do standard (Cintra, 1971; Brissos, 2018). De forma paralela, é possível que regiões tradicionalmente conservadoras como o Nordeste estejam, por via de não terem uma independência linguística tão vincada como o Noroeste, a ser absorvidas com mais facilidade pelo standard, que hoje dispõe de meios de propagação de que nunca dispôs. As variantes com vogal média ocorrem mais frequentemente no resto do território: sem nasalização na faixa diagonal acima indicada e com nasalização nas restantes. A presença na variedade padrão da vogal média com menos ou nenhuma nasalização pode ser entendida como mais um traço relativamente inovador desta variedade face às outras realizações possíveis da vogal /a/ na estrutura em análise. As diferenças de frequência, registadas nos dialetos centro-meridionais entre as regiões do Interior e Sul face às do litoral do Alentejo (já reportadas por Brissos, 2015:1008) bem como às da Estremadura e Ribatejo, parecem estar relacionadas com o menor contacto com a região do padrão das regiões Interior e Sul. Este padrão de diferenciação entre dialetos centro-meridionais reforça, de resto, o que foi registado, a partir de um corpus exaustivo de fenómenos fonológicos e morfossintáticos, por Brissos (2016:100).

Além da nasalização, encontram-se em convivência com a NRH alterações importantes nas estruturasalvo, em particular no Noroeste, no Centro Interior e no Algarve (nas três «regiões subdialetais com características peculiares bem diferenciadas» que Cintra, 1971, identifica). Os processos que analisámos parecem ser independentes da NRH, à exceção da elevação de /a/. A partir das observações de todas as

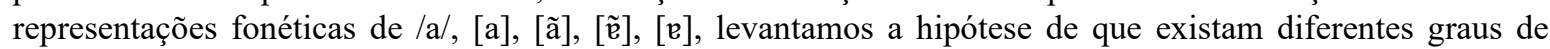
nasalidade em diferentes falantes e regiões e, em consequência, diferentes sensibilidades ao traço por parte dos falantes. Isso parece-nos plausível tendo em conta o facto de, nas regiões referidas onde predomina a forma desnasalizada [e], os falantes não parecerem ter consciência de produzir a nasalidade, mas outros falantes a poderem reconhecer na pronúncia deles. É claro que a pronúncia de [e] reforça a distinção da nossa estruturaalvo face à das outras vogais nasais, ou seja, as que são afetadas pela nasalização tautossilábica ou mesmo as que derivam de estruturas onde a consoante nasal foi elidida, ex. lana > lãa > lã. Quem a utiliza tenderá a não a perceber, a não ser na fala dos falantes de outros dialetos, ao passo que os restantes falantes tendem a percebêla, mesmo que seja menos forte do que a que ocorre nas restantes estruturas e dialetos. A eventual desvalorização percetiva da presença de NRH poderia estar na origem da progressiva produção de formas cada vez menos nasalizadas, nomeadamente na variedade padrão; pelo contrário, a maior valorização percetiva do grau de nasalidade dos falantes de outras origens poderia justificar a sua perceção em situações em que esta não existe ou existe em baixo grau. Nessa medida, testes de produção e de perceção devem ser realizados no futuro para explorar essas questões. O presente trabalho, baseado nos abundantes dados dialetais do ALEPG, dá a conhecer os contornos da variação em Portugal continental relativos à NRH nas estruturas com a vogal /a/ acentuada e as três consoantes nasais, estimulando assim a investigação futura do fenómeno no momento atual da língua, uma vez que os dados aqui analisados foram quase todos recolhidos no último quartel do século XX. 


\section{Referências:}

Andrade, E. d' e A. Kihm (1987) Fonologia autossegmental e nasais em português. Actas do $3^{\circ}$ Encontro da Associação Portuguesa de Linguística. Lisboa, pp. 51-60 (2 ${ }^{\mathrm{a}}$ ed. em 1992. In Ernesto d'A. Temas de Fonologia. Lisboa, pp. 131-138).

Archangeli, D. B. (1988) Aspects of Underspecification Theory. In Phonology Yearbook. Cambridge University Press, 5(2), pp. 183-207.

Battisti, E. (1997) A nasalização no português brasileiro e a redução dos ditongos nasais átonos: uma abordagem baseada em restrições. Dissertação de doutoramento em Letras: Linguística Aplicada, Faculdade de Letras, PUCRGS.

Botelho, J. M. (2007) A nasalidade das vogais em português. SOLETRAS. São Gonçalo: UERJ, 7(14), pp. 5563.

Brissos, F. (2015) Dialectos portugueses do Centro-Sul: corpus de fenómenos e revisão do problema da (des)unidade. Zeitschrift für romanische Philologie. 131(4), pp. 999-1041. [Em linha]. Disponível em: https://doi.org/10.1515/zrp-2015-0071. [Consultado em 06-04-2020].

Brissos, F. (2016) Portugal: a cidade e o interior. I - Centro-sul. In Limite 10.1, pp. 85-107. Disponível online em http://www.revistalimite.es/volumen\%2010/05brissos.pdf.

Brissos, F. (2018) Proposta de reformulação da classificação dialetal do noroeste português. In Estudos de Lingüística Galega, volume especial I, pp. 193-208. Disponível online em http://www.usc.es/revistas/index.php/elg/article/view/3560.

Câmara, Jr., J. M. (1970) Estrutura da língua portuguesa. Petrópolis: Vozes, $8^{\text {a ed. }}$

Clements, G. N. e E. Hume (1995) The Internal organization of Speech Sounds. In Goldsmith, J. The Handbook of Phonological Theory. Cambridge: Blackwell, pp. 245-306.

Cintra, L. F. L. (1971) Nova proposta de classificação dos dialectos galego-portugueses. In Boletim de Filologia. Lisboa: Centro de Estudos Filológicos, 22, pp. 81-116.

CLUL (n.d.) Atlas Linguístico-Etnográfico de Portugal e da Galiza. [Em linha]. Disponível em: https://clul.ulisboa.pt/projeto/alepg-atlas-linguistico-etnografico-de-portugal-e-da-galiza. [Consultado em 22-12-2019].

Florêncio, M. (2001) Dialecto alentejano: contributos para o seu estudo. Lisboa: Edições Colibri e Centro de Estudos do Alentejo, $2^{\mathrm{a}}$ ed.

Goldsmith, J. (1990) Autosegmental and metrical phonology. Oxford: Basil Blackwell.

Goodin-Mayeda, C. E. (2016) Nasals and nasalization in Spanish and Portuguese. Amsterdam/Philadelphia: Jonh Benjamins Publishing Company.

Mateus, M. H. M. e E. d'Andrade (2000) The phonology of Portuguese. Oxford: Oxford University Press.

Moraes, J. A. e W. L. Wetzels (1992) Sobre a Duração dos Segmentos Vocálicos Nasais e Nasalizados em Português. Um Exercício de Fonologia Experimental. In Caderno de estudos linguísticos. Campinas, (23), pp. 153-166,

Moraes, J. A. (2013) Produção e percepção das vogais nasais. In Abaurre, M. B. M. Gramática do português culto falado no Brasil: A construção fonológica da palavra. São Paulo: Contexto, 7, pp. 95-112.

Pimenta, H. (2019) Nasalité et syllabe: une étude synchronique, diachronique et dialectologique du portugais européen. Dissertação de doutoramento em Ciências de Língua, Université Paris 8 - Vincennes - Saint Denis.

Rodrigues, C. (2002a) Questões de espraiamento em PE. Actas do XVII Encontro Nacional da Associação Portuguesa de Linguística. Lisboa, pp. 419-432.

Rodrigues, C. (2002b) Variação linguística em Porto. Actas do Encontro Comemorativo dos 25 anos do CLUP. Porto, 1, pp. 119-130.

Sampson, Rodney (1999) Nasal Vowel Evolution in Romance. Oxford: Oxford University Press. 
Saramago, J. (2006) O Atlas Linguístico-etnográfico de Portugal e de Galiza (ALEPG). In Estudis Romànics. XXVIII. Barcelona: Institut d'Estudis Catalans, pp. 281-298.

Segura, L. e J. Saramago (1999) Madeira e Açores: autonomia e coesão dialectais. In Faria, I. Hub Lindley

Cintra: Homenagem ao homem, ao mestre e ao cidadão. Lisboa: Edições Cosmos, pp. 707-738.

Vasconcelos, J. L. de (1901) Esquisse d'une Dialectologie Portugaise. Thèse pour le doctorat de l'Université de

Paris, Faculté des Lettres. Paris: Aillaud (2a ed. em 1970).

Vasconcelos, J. L. de (1928) Opúsculos. Vol. II. Dialectologia. Coimbra: Imprensa da Universidade.

Vasconcelos, J. L. de (1985) Opúsculos. Vol. VI. Dialectologia. Coimbra: Imprensa da Universidade.

Vázquez Cuesta, P. e M. A. Mendes da Luz (1980). Gramática da língua portuguesa. Lisboa: Edições 70.

\section{Anexo}

Anexo 1 Pontos de inquérito do ALEPG (continentais)

\begin{tabular}{|c|c|c|c|c|c|}
\hline Sigla & Localidade & Sigla & Localidade & Sigla & Localidade \\
\hline A & Aveiro & $\mathrm{B}$ & Beja & $\mathrm{Bc}$ & Bragança \\
\hline A1 & Espinho & B1 & Peroguarda & $\mathrm{Bç} 1$ & Riodonor \\
\hline A2 & Cesar & B2 & Quintos & $\mathrm{Bç} 2$ & Guadramil \\
\hline A3 & Válega & B3 & Serpa & $\mathrm{Bç3}$ & Constantim \\
\hline A4 & Carvoeiro & B4 & Zambujeira do Mar & $\mathrm{Bç} 4$ & Sendim \\
\hline A5 & Covo & B5 & Barrancos & $\mathrm{Bç} 5$ & Duas Igrejas \\
\hline A6 & Moitinhos & B6 & Álamo $^{13}$ & Bç6 & Ribalonga \\
\hline \multirow[t]{2}{*}{ A7 } & Pardeeiro & B7 & Nave Redonda & Bç7 & Sambade \\
\hline & & B8 & Aljustrel & Bç8 & Penas Roias \\
\hline $\mathrm{Br}$ & Braga & B9 & Mesquita & Bç9 & Lanção \\
\hline $\mathrm{Br} 1$ & S. Romão da Ucha & $\mathrm{B} 10$ & Moura & Bç10 & Algoso \\
\hline $\mathrm{Br} 2$ & Gondomar das & B11 & Panóias & Bç11 & Outeiro \\
\hline $\mathrm{Br} 3$ & Vila Boa de Bucos & B12 & Porteirinhos & Bç12 & Mazouco \\
\hline $\mathrm{Br} 4$ & S. João do Campo & B13 & S. Barnabé & Bç13 & Ala \\
\hline $\mathrm{Br} 5$ & Fiscal & B14 & Corte Cobres & Bç14 & Travanca \\
\hline Br6 & Soutelo & $\mathrm{B} 15$ & Luzianes & Bç15 & Marmelos \\
\hline $\mathrm{Br} 7$ & Gagos & & & Bç16 & Larinho \\
\hline \multirow[t]{2}{*}{ Br8 } & Pousada de & $\mathrm{CB}$ & Castelo Branco & & \\
\hline & & CB1 & Idanha-a-Nova & $\mathrm{E}$ & Évora \\
\hline $\mathrm{C}$ & Coimbra & CB2 & Monsanto & E1 & S. Romão \\
\hline $\mathrm{C} 1$ & Folques & CB3 & Malpica do Tejo & E2 & Alcáçovas \\
\hline $\mathrm{C} 2$ & Murtinheira & CB4 & Salvaterra do Extremo & E3 & Arraiolos \\
\hline C3 & Mira & CB5 & Alcongosta & E4 & Nossa Senhora de Machede \\
\hline $\mathrm{C} 4$ & Porto de Vacas & CB6 & Cardosa & E5 & Carrapatelo \\
\hline $\mathrm{C} 5$ & Ervedal da Beir & CB7 & Foz do Cobrão & E6 & Lavre \\
\hline C6 & Casconh & CB8 & Rosmaninhal & E7 & Baldios \\
\hline $\mathrm{C7}$ & Papanata & CB9 & Unhais da Serra & E8 & S. Lourenço de Mamporcão \\
\hline $\mathrm{C} 8$ & Figueira de Lorvão & CB10 & Isna & E9 & Santana \\
\hline C9 & Vila Pouca do & & & E10 & Terena \\
\hline
\end{tabular}

\footnotetext{
${ }^{13}$ Este ponto de inquérito é excluído neste trabalho porque os seus materiais estão em tratamento.
} 


\begin{tabular}{|c|c|c|c|c|c|}
\hline & & $\mathrm{G}$ & Guarda & & \\
\hline $\mathrm{F}$ & Faro & G1 & Monteiros & $\mathrm{L}$ & Leiria \\
\hline F1 & Praia da Salema & G2 & Escalhão & L1 & Ferrel \\
\hline F2 & Santa Luzía (de & G3 & Sortelha & $\mathrm{L} 2$ & Vieira de Leiria \\
\hline F3 & Fuseta & G4 & Sabugueiro & L3 & Boca da Mata \\
\hline F4 & Vila do Bispo & G5 & Seixas & L4 & Mosteiro \\
\hline F5 & Marmelete & G6 & Barreira & L5 & Moita do Martinho \\
\hline F6 & Quarteira & G7 & Vale da Mula & L6 & Cela Velha \\
\hline F7 & Parises & G8 & Fóios & L7 & Antões \\
\hline F8 & Alvor & G9 & Poço Velho & & \\
\hline F9 & Encheirim & G10 & Pala & $\mathrm{Lx}$ & Lisboa \\
\hline F10 & Aljezur & G11 & Figueiró da Serra & Lx1 & Fontanelas \\
\hline F11 & Alta Mora & & & Lx2 & Aldeia Galega \\
\hline F12 & Alte & $\mathrm{Pl}$ & Portalegre & Lx3 & Freixial \\
\hline F13 & S. Marcos da Serra & Pl1 & Alegrete & $\mathrm{Lx} 4$ & Dagorda \\
\hline F14 & Laranjeiras & $\mathrm{P} 12$ & Alpalhão & Lx5 & Póvoa de Penafirme \\
\hline F15 & Penteadeiros & $\mathrm{Pl3}$ & Nisa & Lx6 & Enxara do Bispo \\
\hline \multirow[t]{2}{*}{ F16 } & Junqueira & P14 & Aldeia da Mata & & \\
\hline & & $\mathrm{P} 15$ & Porto da Espada & $\mathrm{S}$ & Santaém \\
\hline $\mathrm{St}$ & Setúbal & P16 & Campo Maior & S1 & Amiais de Baixo \\
\hline St1 & Porto Covo & $\mathrm{P} 17$ & Avis & $\mathrm{S} 2$ & Mesão Frio \\
\hline St2 & Melides & $\mathrm{P} 18$ & Foros do Arrão & S3 & Pereiro \\
\hline St3 & Alcochete & P19 & Cabeço de Vide & S4 & Glória do Ribatejo \\
\hline St4 & Aldeia do Meco & P110 & Vale da Vinha & S5 & Alcanhões \\
\hline St5 & Palma & & & S6 & Montalvo \\
\hline St6 & Foros da Casa Nova & $\mathrm{P}$ & Porto & S7 & Santa Justa \\
\hline St7 & Água Derramada & P1 & Baião & S8 & Parreira \\
\hline \multirow[t]{2}{*}{ St8 } & Canha & $\mathrm{P} 2$ & Gião & S9 & Igreja Nova do Sobral \\
\hline & & P3 & Sardoura (Distr. Aveiro) & & \\
\hline VR & Vila Real & P4 & Sobrado & $\mathrm{V}$ & Viseu \\
\hline VR1 & Santo André & P5 & Barrosas & V1 & Lajeosa do Dão \\
\hline VR2 & Pitões das Júnias & & & V2 & Múceres \\
\hline VR3 & Mondrões & $\mathrm{VC}$ & Viana do Castelo & V3 & Tibaldinho \\
\hline VR4 & Perafita & $\mathrm{VC} 1$ & Moledo & V4 & Granjal \\
\hline VR5 & Ribeira da Fraga & $\mathrm{VC} 2$ & S. Lourenço da Montaria & V5 & Santar \\
\hline VR6 & Sonim & $\mathrm{VC} 3$ & Castro Laboreiro & V6 & Mezío \\
\hline VR7 & Sedielos & VC4 & Estrica & V7 & Malhada \\
\hline VR8 & Roalde & VC5 & Bade & V8 & Granja do Tedo \\
\hline VR9 & Covas do Barroso & VC6 & Fornelos & V9 & Rãs \\
\hline \multirow[t]{2}{*}{ VR10 } & Vidoedo & VC7 & Castelo do Neiva & V10 & Vila Verde \\
\hline & & VC8 & Arcos de Valdevez & V11 & Ester de Cima \\
\hline
\end{tabular}


Anexo 2 Conceitos com a estrutura /a/.C[+nas] de nomes e adjetivos

\begin{tabular}{|l|l|l|l|l|l|}
\hline código & conceito & código & conceito & código & conceito \\
\hline 0384 & aranha & 0064 & lama & 0154 & cana \\
\hline $0384 \mathrm{a}$ & aranha de pernas & 0180 & ramo & 0224 & ratazana \\
\hline 0681 & tacanho & 0180.1 & rama & 0441 & pestana \\
\hline 0712 & picanha & 0229 & cama da lebre & 0739 & \multirow{2}{*}{ roldana } \\
\hline 0780 & coanha & 1307 & enxame & 1073.5 & \\
\hline 0932 & castanha & $1307 \mathrm{a}$ & exame pequeno & 0752 & pragana \\
\hline 0983 & apanha (da azeitona) & 1559 & cama & $0794 \mathrm{a}$ & cana do milho \\
\hline 1135 & rebanho & 1580 & chama & $0794 \mathrm{~b}$ & meda de canas de \\
\hline $1135.1 \mathrm{a}$ & rebanho de bois & 1691 & ama & $0814 \mathrm{D}$ & carreta alentejana \\
\hline 1135.1 & rebanho de vacas & 1797.4 & damos & 1133 & cabana \\
\hline 1135.2 & rebanho de cabras & 1842 & Domingo de Ramos & 1176 & badana \\
\hline 1135.3 & rebanho de ovelhas & 1870 & dama & 1240 & tutano \\
\hline 1136 & rebanho pequeno & 1569 & fazer (a cama) & 1583 & abano \\
\hline $1136 \mathrm{a}$ & rebanho do pastor & & & 1627 & escano \\
\hline 1143 & gadanha & & & 1835 & ano novo \\
\hline 1179 & anho-cordeiro-borrego & & & 2045 & semana \\
\hline 1243 & banha & & & 2067 & ano \\
\hline 1672 & banhos & & & 2068 & este ano \\
\hline 1917 & castanho & & & 2069 & o ano passado \\
\hline 1917.1 & (cabelo) castanho & & & 2070 & bissexto (ano) \\
\hline 0545 & ranho & & & & \\
\hline
\end{tabular}

